OPEN ACCESS

Edited by:

Bas E. Dutilh,

Utrecht University, Netherlands

Reviewed by:

Gerard Hoyne,

University of Notre Dame Australia, Australia

Laura Baldomà,

University of Barcelona, Spain

*Correspondence: Megan T. Baldridge mbaldridge@wustl.edu

${ }^{\text {t}}$ These authors have contributed equally to this work

Specialty section:

This article was submitted to Microbiome in Health and Disease,

a section of the journal

Frontiers in Cellular and

Infection Microbiology

Received: 24 July 2020 Accepted: 23 November 2020 Published: 08 January 2021

Citation: Kim AH, Hogarty MP, Harris VC and Baldridge MT (2021) The Complex Interactions Between Rotavirus and the Gut Microbiota. Front. Cell. Infect. Microbiol. 10:586751. doi: 10.3389/fcimb.2020.586751

\section{The Complex Interactions Between Rotavirus and the Gut Microbiota}

\author{
Andrew Hyoung Jin Kim ${ }^{1+}$, Michael P. Hogarty ${ }^{1 \dagger}$, Vanessa C. Harris ${ }^{2}$ \\ and Megan T. Baldridge ${ }^{1 *}$ \\ ${ }^{1}$ Department of Medicine, Division of Infectious Diseases, Washington University School of Medicine, St. Louis, MO, \\ United States, ${ }^{2}$ Department of Medicine, Division of Infectious Diseases and Department of Global Health (AlGHD), \\ Amsterdam University Medical Center, Academic Medical Center, Amsterdam, Netherlands
}

Human rotavirus (HRV) is the leading worldwide cause of acute diarrhea-related death in children under the age of five. RV infects the small intestine, an important site of colonization by the microbiota, and studies over the past decade have begun to reveal a complex set of interactions between RV and the gut microbiota. RV infection can temporarily alter the composition of the gut microbiota and probiotic administration alleviates some symptoms of infection in vivo, suggesting reciprocal effects between the virus and the gut microbiota. While development of effective $R V$ vaccines has offered significant protection against RV-associated mortality, vaccine effectiveness in lowincome countries has been limited, potentially due to regional differences in the gut microbiota. In this mini review, we briefly detail research findings to date related to HRV vaccine cohorts, studies of natural infection, explorations of RV-microbiota interactions in gnotobiotic pig models, and highlight various in vivo and in vitro models that could be used in future studies to better define how the microbiota may regulate RV infection and host antiviral immune responses.

Keywords: rotavirus (human and animal), microbiota, immunity, rotavirus vaccine, animal models, in vitro models

\section{INTRODUCTION}

Prior to the introduction of rotavirus vaccines (RVVs) in 2006, human rotavirus (HRV) was the leading global cause of mortality due to acute gastroenteritis in children under the age of five (Rodriguez et al., 1980; Tate et al., 2016). Despite successful implementation of the vaccine, RV still accounts for the higest numbers of death due to gastroenteritis globally. RV is a double-stranded RNA virus in the Reoviridae family. RV virions are non-enveloped and composed of three concentric protein layers, which contain a genome of 11 segments of dsRNA encoding 6 structural proteins and 6 non-structural proteins (Desselberger, 2014). RV predominantly targets mature enterocytes in the small intestine, and infection is regulated by both innate and adaptive immune responses (Greenberg and Estes, 2009). The RVV has significantly decreased HRVassociated mortality rates but both the efficacy and effectiveness of RVV in preventing severe gastroenteritis in children is significantly lower in low-income vs high-income settings (Parashar et al., 2003; O'Ryan, 2017). As one of the possible etiologies contributing to this variation in RVV effectiveness, a number of recent studies have suggested a potential role for the commensal gut microbiota in regulating RVV responses (Harris et al., 2017a; Harris et al., 2017b; Harris, 2018; 
Harris et al., 2018). This review details what is currently understood about the complex interactions between RV infection and immunity and the gut microbiota, summarizing the evidence to date as well as clarifying the in vitro and in vivo systems available to explore these interactions.

\section{INTERACTIONS BETWEEN HUMAN ROTAVIRUS AND THE GUT MICROBIOTA}

HRV infects the intestine, which also hosts the human body's largest collection of microorganisms. As understanding of the broad physiological importance of the commensal gut microbiota has grown (Kennedy et al., 2018), so has interest in its interactions with pathogens. Enteric viruses, including RV, norovirus, adenovirus and astrovirus, induce diarrhea, which can alter the human gut microbiome by shifting the dominant phylum from Bacteroidetes to Firmicutes, decreasing bacterial diversity and increasing opportunistic pathogens, such as the genera Shigella (Ma et al., 2011). HRV-induced gastroenteritis has been specifically shown to temporarily decrease the diversity of and significantly alter the microbiota composition after infection, though recovery is associated with return to a level of diversity that reflects the non-infected state (Chen et al., 2017; Dinleyici et al., 2018). In addition to broad phylogenetic changes, species-specific shifts after HRV infection have also been reported, such as a transition from Bacteroides vulgatus and stercoris to Bacteroides fragilis, suggesting structural changes to the gut microbiota at all taxonomic levels (Zhang et al., 2009). Thus, HRV infection and associated diarrheal illness clearly affect the intestinal bacterial microbiota. Importantly, however, there is increasing appreciation that the interactions between HRV and the gut microbiota are bidirectional, and that the gut microbiota can also influence the intensity and duration of HRV infection (Saavedra et al., 1994; Fang et al., 2009; Teran et al., 2009; Grandy et al., 2010; Huang et al., 2014; Lee et al., 2015).

There have been persistent efforts to define the effects of the gut microbiota on human RV infection. Several clinical trials, either conducted pre-RVV in the United States or post-RVV in Bolivia, Taiwan, and Korea, have investigated the effects of probiotic administration on infants and children with natural symptomatic RV infection (Saavedra et al., 1994; Fang et al., 2009; Teran et al., 2009; Grandy et al., 2010; Huang et al., 2014; Lee et al., 2015). In these studies, probiotics including Lactobacillus rhamnosus, Saccharomyces boulardii, and Bifidobacterium longum resulted in mild to moderate reduction of RV-associated symptoms, such as duration of diarrhea and fecal RV levels. However, another prospective, randomized, double-blind trial conducted post-RVV in the United States failed to identify a protective effect for L. rhamnosus GG in protecting children against acute gastroenteritis (Schnadower et al., 2018). Probiotic administration, in conjunction with traditional treatment such as oral rehydration, may thus have potential as a therapeutic intervention for $\mathrm{RV}$-induced gastroenteritis in some settings, but the mechanisms by which these bacterial taxa affect $\mathrm{RV}$ infection in humans remain unclear. Studies using an in vivo model of HRV infection have the potential to shed additional light on these interactions.

Neonatal gnotobiotic pigs recapitulate many physiological factors of human infants (Meurens et al., 2012) and are susceptible to HRV infection (Saif et al., 1996), making them a useful animal model to investigate the interactions between the gut microbiota and HRV (Yuan and Saif, 2002; Zhang et al., 2008a; Kandasamy et al., 2016; Paim et al., 2016; Kumar et al., 2018). Transplantation of the gut microbiota of human infants to neonatal gnotobiotic pigs permitted evaluation of the impact of diet on both the gut microbiota composition and HRV disease severity (Kumar et al., 2018). Post-transplant, the piglets shared the majority of bacterial taxa identified in the original sample, and colonized piglets were observed to have reduced HRVinduced diarrhea and viral shedding compared to their noncolonized germ-free counterparts. In addition, a proteinsufficient diet further limited the severity of infection compared to a protein-deficient diet, suggesting that proper nutrition can also be protective, potentially via maintenance of the microbiota (Kumar et al., 2018). Similar to the human cohort studies discussed above, neonatal gnotobiotic pigs have been used to test the effects of various probiotics such as Escherichia coli Nissle 1917, Lactobacillus rhamnosus GG, Lactobacillus acidophilus, and Lactobacillus reuteri on HRV infection (Zhang et al., 2008a; Kandasamy et al., 2016; Paim et al., 2016). In general, these studies have supported the beneficial effects of probiotic use in limiting the symptoms of HRV infection or enhancing B cell responses. E. coli Nissle administration has been shown to reduce diarrhea severity and HRV shedding in pigs by both increasing IL-6, IL-10, and IgA levels as well as potentially directly binding RV particles (Kandasamy et al., 2016). Furthermore, E. coli Nissle altered gene expression in several enteric cell types and reduced enterocyte proliferation, implicating the probiotic in reducing barrier disruption and maintaining the absorptive function of the gut (Paim et al., 2016). In contrast, colonization of germ-free neonatal pigs with lactic acid bacteria probiotics alone was insufficient to promote intestinal B cell responses (Zhang et al., 2008a). An important caveat of these studies is that though neonatal pigs recapitulate many aspects of HRV infection in human infants, there is always the possibility that probiotic effects observed are unique to piglets. Since enhancement of immune responses is key for these potential therapeutic interventions, further investigations are needed to fully resolve the effect of these probiotics on HRV immune responses.

\section{INTERACTIONS BETWEEN ROTAVIRUS VACCINES AND THE GUT MICROBIOTA}

Rotarix and Rotateq, two different types of live-attenuated oral RVVs, are currently the most studied RVV. Rotarix is a monovalent, attenuated vaccine derived from HRV strain G1P [8] (Ward and Bernstein, 2009) and licensed by the FDA with a dosage regimen of two oral doses at 6 and 10 weeks of age (Payne et al., 2011). Rotateq is a pentavalent human-bovine vaccine containing five $\mathrm{RV}$ reassortants derived from human and bovine 
viral species (Vesikari et al., 2009) and licensed by the FDA with a dosage regimen of three oral doses at 2, 4, and 6 months of age (Payne et al., 2011). In high-income settings, both vaccines show over $85 \%$ efficacy in preventing severe RV gastroenteritis in infants, and effectively increase anti-RV serum IgA, which is highly correlated with RVV efficacy (Vesikari et al., 2006; Patel et al., 2013). Prior studies, examining phylum-level differences, indicate RVV administration does not broadly affect the microbiota (Garcia-Lopez et al., 2012; Ang et al., 2014).

In contrast, a number of recent studies exploring species-level differences have implicated the gut microbiota in regulating RVV efficacy. The gut microbiota factors responsible for the variation in RVV efficacy have been explored in various clinical studies with cohorts from different regions including Ghanaian, Pakistani, Finnish, Indian, and Nicaraguan infants (Isolauri et al., 1995; Harris et al., 2017a; Harris et al., 2017b; Harris et al., 2018; Lazarus et al., 2018; Parker et al., 2018; Fix et al., 2020). These studies suggest that geographical differences in gut bacterial composition may contribute to RVV efficacy, and indeed specific bacterial taxa have been associated with RVV responses, including a positive correlation for Streptococcus bovis and a negative correlation with members of the Bacteroidetes phylum with anti-RV IgA responses (Harris et al., 2017a; Harris et al., 2017b) (Figure 1A). In other cohorts, no association of specific microbiota taxa with seroconversion was found. These discrepancies may derive from differences in microbiome sequencing methodologies, or in distinct gut microbiota composition influenced by different geographical regions (Parker et al., 2018; Fix et al., 2020). A proof-of-principle study tested whether prospective alteration of the microbiota with narrow-spectrum (vancomycin alone) or broad-spectrum (vancomycin, ciprofloxacin and metronidazole) antibiotics could modulate RVV immunogenicity in adults. Significantly decreased levels of Firmicutes and increased level of Proteobacteria in the narrow-spectrum group correlated with enhanced anti-RV IgA, but not IgG, titer boosting as well as increased RVV shedding (Harris et al., 2018). However, the specific mechanism of how bacterial taxa may regulate RV immune responses, including anti-RV $\operatorname{IgA}$, has not yet been defined.

Currently available oral rotavirus vaccine efficacy is generally considered comparable across low- and middle-income settings.

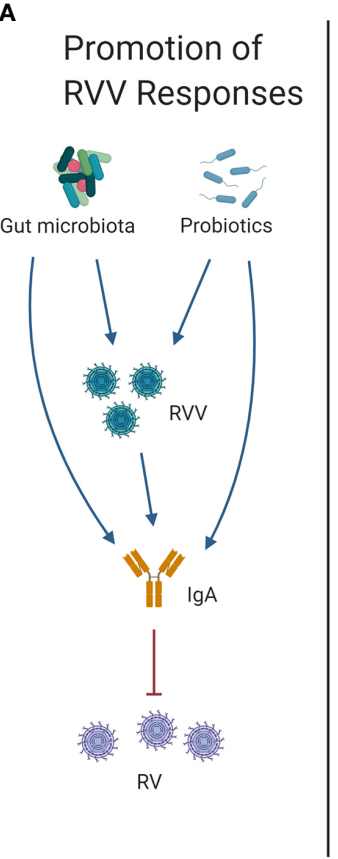

B

\section{Prevention of RV Infection}
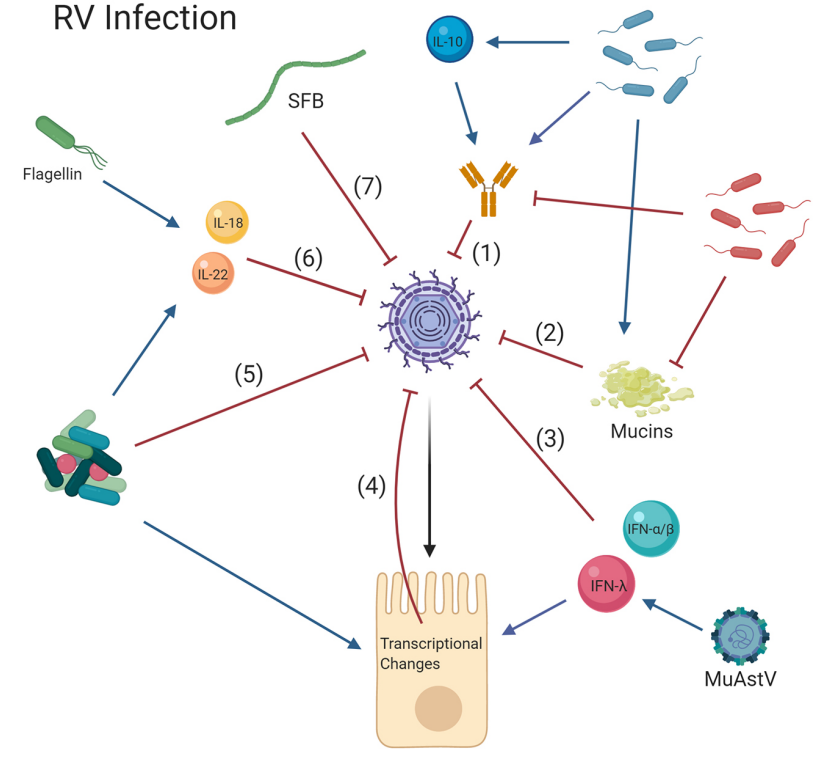

FIGURE 1 | Effects of the gut microbiota on rotavirus vaccines (RW) and rotavirus (RV) infection. (A) Promotion of RW Responses: Gnotobiotic pig studies have suggested that overall, the gut microbiota and specific probiotics promote RW efficacy and the development of protective IgA responses, which in turn limit future RV infection. (B) Prevention of RV infection: Clinical trials as well as studies in gnotobiotic pigs and neonatal rats have shown that the commensal microbiota and probiotics may also reduce symptoms of RV infection, partially through development of increased IL-10 levels and anti-RV IgA (1). Murine and gnotobiotic neonatal rat models have shown probiotics may reduce RV infection by inducing mucin secretion (2). Alternately, some studies in mice have shown that bacteria may facilitate $\mathrm{RV}$ infection by limiting anti-RV IgA responses and degrading mucins which potentially prevent RV-cell attachment (1, 2). Cytokines type I (IFN- $\alpha / \beta)$ and III IFNs (IFN$\lambda$ ) are also antiviral (3), and virome element murine astrovirus (MuAstV) can protect against RV by inducing IFN- $\lambda$, thereby upregulating interferon stimulated genes (ISG) (4). Gnotobiotic pig studies have indicated that probiotics can inhibit RV infection and reduce disturbance of the intestinal barrier as observed through increased Villin, Muc2, CgA, and Pcna and decreased Sox9 expression, indicating restoration of differentiated enterocyte, goblet, enteroendocrine and transient amplifying progenitor cell function and decreased proliferation of stem cells, respectively (4). Bacteria can also directly interact with RV particles, which may reduce infection (5). Studies in mice have shown that elements of the gut microbiota including bacterial flagellin can activate IL-18 and IL-22 signaling to protect against RV (6). Segmented filamentous bacteria (SFB) can also prevent RV infection through immune cell-independent mechanisms (7). 
Increasing numbers of generic oral vaccines are available on the market and they differ in terms of number of doses, timing of doses, and cost. Choice of vaccines in low- and middle-income settings is often driven by cost, support from the Global Alliance for Vaccines and Immunization, feasibility of integration with existing vaccination programs, and availability. There are many regional factors including maternal antibodies, viral co-infection, host genetics, diet, and other geographic differences that may contribute to diminished RVV protection in low- and middleincome settings along-side the microbiota. Currently, all human studies evaluating correlations between RVV and intestinal microbiota have evaluated RVV immunogenicity and not vaccine efficacy against severe RV gastroenteritis. RV immunogenicity, as measured by anti-RV IgA is an imperfect correlate of protection and may not reflect protection from clinically relevant disease. Additional region-specific investigations are therefore needed, evaluating the microbiota's correlation with vaccine efficacy against severe RV gastroenteritis in order to clarify the effects of the gut microbiota on RVV performance, with subsequent validation in in vivo models (Burke et al., 2019).

Gnotobiotic pigs have also been used to examine the effect of the gut microbiota on RVV efficacy and vice-versa (Zhang et al., 2008b; Vlasova et al., 2013; Kandasamy et al., 2014; Zhang H. et al., 2014; Twitchell et al., 2016). Enhanced cell-mediated immunity, as measured by more RV-specific IFN- $\gamma$ producing $\mathrm{T}$ cells, in response to RVV was observed in neonatal gnotobiotic pigs transplanted with healthy infant gut microbiota compared to an unhealthy infant gut microbiota, though RV-specific IgA, $\mathrm{IgG}$, and virus neutralizing antibody responses were unaffected. (Twitchell et al., 2016). L. rhamnosus GG administration to pigs, which had also received transplanted human gut microbiota and RVV, prevented the phylum-level shift from Firmicutes to Proteobacteria caused by HRV challenge, but had no significant effect on HRV infection responses (Zhang $\mathrm{H}$. et al., 2014). In contrast, other reports suggest that colonization of neonatal gnotobiotic pigs with L. rhamnosus GG and Bifidobacterium animalis lactis Bb12, followed by RVV vaccination, significantly enhances RVV immunogenicity and diminishes HRV infection responses including severe diarrhea and viral shedding (Vlasova et al., 2013; Kandasamy et al., 2014) (Table 1). However, these results were not fully replicated in human clinical trials, wherein L. rhamnosus GG treatment had a positive but very modest or no significant effect on RVV immunogenicity (Isolauri et al., 1995; Lazarus et al., 2018). The factors responsible for diminished probiotic effectiveness in humans remain unresolved, and additional studies involving transplantation of human infant gut microbiota in neonatal gnotobiotic pigs may help to resolve which factors will help drive immunologically relevant responses in humans.

\section{Models for Studying Rotavirus Infection and Immunity}

Beyond gnotobiotic pig models described above, murine models have been beneficial to understand the mechanisms through which the microbiota interacts with RV (Figure 1B). Multiple strains of murine rotavirus $(\mathrm{mRV})$ are available, and adult mice are susceptible to infection. However, only mice under 14 days of age develop diarrhea (Greenberg and Estes, 2009), which is a significant means by which infection can alter the intestinal microbiota (Ma et al., 2011). BALB/c mice have been shown to be approximately 1,000 times more susceptible to infection than C57BL/6 mice, suggesting important, and still unclear, mechanisms of genetic regulation of susceptibility (Blutt et al., 2012).

MRV infection causes significant changes to the composition of the ileal microbiota by inducing mucin secretion from goblet cells (Engevik et al., 2020). This compositional shift favors mucin-degrading bacteria Bacteroides and Akkermansia, which in turn could also promote $\mathrm{mRV}$ infection in vitro. Furthermore, ampicillin and neomycin administration has been linked to protection against $\mathrm{mRV}$ infection and symptoms via generation of a more robust humoral/mucosal response, further implicating the microbiota in promoting $\mathrm{mRV}$ infection (Uchiyama et al., 2014).

Conversely, probiotics Bifidobacterium bifidum, Bifidobacterium dentium, and Bifidobacterium longum mediate protective effects against $\mathrm{mRV}$ infection, potentially via increased mucin secretion, which can prevent efficient RV cell attachment (Chen et al., 1993; Duffy et al., 1994a; Duffy et al., 1994b; Boshuizen et al., 2005; Munoz et al., 2011; Kawahara et al., 2017; Engevik et al., 2019). Microbes such as Lactobacillus reuteri and Bifidobacterium species can also hamper infection by increasing $\mathrm{mRV}$-specific IgA levels (Qiao et al., 2002; Preidis et al., 2012). Recently, segmented filamentous bacteria (SFB) have been found to inhibit mRV infection in an immune cellindependent manner, possibly by changes in host gene expression, accelerated epithelial cell turnover, and/or direct neutralization (Shi et al., 2019).

Regulation of critical antiviral cytokine pathways is an important mechanism for microbiota-mediated regulation of RV. Bacterial flagellin mediates antiviral effects via toll-like receptor 5 and NOD-like receptor C4-mediated activation of cytokines interleukin-22 (IL-22) and IL-18, which protect against RV infection (Zhang B. et al., 2014). IL-22 has been shown to be profoundly antiviral against RV, especially in combination with mucosal antiviral cytokine interferon-lambda (IFN- $\lambda$ ) (Hernandez et al., 2015). Type I (IFN- $\alpha / \beta)$ and III IFNs (IFN$\lambda$ ) are induced by RV and exert age-dependent antiviral effects against RV (Broquet et al., 2011; Pott et al., 2011; Lin et al., 2016; Ingle et al., 2018). We recently found that a non-bacterial element of the microbiota, specifically chronic murine astrovirus infection in immunocompromised mice, stimulates high levels of IFN- $\lambda$, but not type I or II IFNs, to protect mice against RV infection (Ingle et al., 2019), indicating that the virome can have important interactions with $\mathrm{RV}$ as well. Murine models of RV are thus helpful for clarifying mechanisms and molecular pathways by which the microbiota can promote or prevent infection.

Neonatal rats have also been used as an animal model to study effects of probiotics on RV infection. Rats can be readily infected using simian RV (SRV) strain SA-11, rare reassortants of which have been shown to infect humans (Ciarlet et al., 2002; Awachat 
TABLE 1 | Effects of microbiota and probiotics, observed in individual studies, on HRV/RWV immune responses in gnotobiotic neonatal pigs.

\begin{tabular}{|c|c|c|c|c|c|c|c|}
\hline Study details & Experimental design & $\begin{array}{l}\text { Gut microbiota or } \\
\text { probiotic source }\end{array}$ & Diarrheal severity & $\begin{array}{l}\text { HRV fecal } \\
\text { shedding }\end{array}$ & Innate Immune Reponses & Humoral Immunity & T cell Responses \\
\hline Zhang et al., 2008b & $\begin{array}{l}\text { Vac+Pro (vaccinated, } \\
\text { probiotics) } \\
\text { Vac (vaccinated, no } \\
\text { probiotics) } \\
\text { Pro (unvaccinated, probiotics) } \\
\text { Control (unvaccinated, no } \\
\text { probiotics) }\end{array}$ & $\begin{array}{l}\text { Lactobacillus } \\
\text { acidophilus strain } \\
\text { NCFM }\end{array}$ & $\begin{array}{l}\text { } \text { in Vac+Pro } \\
\text { compared to Vac }\end{array}$ & no difference & & $\begin{array}{l}\Delta \lg A \text { and } \lg G \text { antibody-secreting } \\
\text { cell responses in ileum, and } \\
\text { serum IgM, IgA and IgG antibody } \\
\text { and virus neutralizing antibody } \\
\text { titers in Vac+Pro compared to } \\
\text { Vac }\end{array}$ & $\begin{array}{l}\text { HRV-specific IFN- } \gamma \\
\text { producing CD8+ T cell } \\
\text { responses in ileum and } \\
\text { spleen in Vac+Pro } \\
\text { compared to Vac }\end{array}$ \\
\hline Vlasova et al., 2013 & $\begin{array}{l}\text { Vac+Pro (vaccinated, } \\
\text { probiotics) -/+ HRV challenge } \\
\text { Vac (vaccinated, no } \\
\text { probiotics) -/+ HRV challenge } \\
\text { Pro (unvaccinated, probiotics) } \\
\text {-/+ HRV challenge } \\
\text { Control (unvaccinated, no } \\
\text { probiotics) -/+ HRV challenge }\end{array}$ & $\begin{array}{l}\text { Lactobacillus } \\
\text { rhamnosus strain GG } \\
\text { Bifidobacterium } \\
\text { animalis lactis strain } \\
\text { Bb } 12\end{array}$ & $\begin{array}{l}\text { Vin all groups + } \\
\text { HRV compared to } \\
\text { Control + HRV }\end{array}$ & $\begin{array}{l}\text { Vin all groups + } \\
\text { HRV compared to } \\
\text { Control + HRV }\end{array}$ & $\begin{array}{l}\Delta \mathrm{pDC} / \mathrm{cDC} \text { and } \mathrm{MHCll}+\mathrm{pDC} / \\
\mathrm{cDC} \text { in ileum and blood of Pro } \\
+ \text { HRV \& Vac+Pro + HRV } \\
\text { compared to Vac + HRV and } \\
\text { Control +HRV } \\
\text { C serum IFN-alpha levels in } \\
\text { Controls + HRV compared to } \\
\text { all other groups + HRV } \\
\nabla \text { TLR } 2 \text { and TLR4 expressing } \\
\text { MNCs from Vac+Pro - HRV } \\
\text { TLR3 expressing MNCs } \\
\text { from Pro + HRV. } \\
\text { M CD4, SWC3a, CD11R1, } \\
\text { MHCll expressing intestinal and } \\
\text { blood MNCs in Pro + HRV \& } \\
\text { Vac+Pro + HRV compared to } \\
\text { Vac + HRV and Control +HRV }\end{array}$ & & \\
\hline $\begin{array}{l}\text { Kandasamy et al., } \\
2014\end{array}$ & $\begin{array}{l}\text { Vac+Pro (vaccinated, } \\
\text { probiotics) -/+ HRV challenge } \\
\text { Vac (vaccinated, no } \\
\text { probiotics) -/+ HRV challenge } \\
\text { Pro (unvaccinated, probiotics) } \\
-/+ \text { HRV challenge } \\
\text { Control (unvaccinated, no } \\
\text { probiotics) -/+ HRV challenge }\end{array}$ & $\begin{array}{l}\text { Lactobacillus } \\
\text { rhamnosus strain GG } \\
\text { Bifidobacterium } \\
\text { animalis lactis strain } \\
\text { Bb } 12\end{array}$ & $\begin{array}{l}\text { Vin Vac+Pro + } \\
\text { HRV compared to } \\
\text { Vac + HRV }\end{array}$ & $\begin{array}{l}\text { in Vac+Pro + } \\
\text { HRV compared to } \\
\text { Vac + HRV }\end{array}$ & $\begin{array}{l}\text { A mature conventional DCs } \\
\text { and plasmacytoid DCs in Vac } \\
\text { +Pro + HRV compared to Vac } \\
\text { + HRV } \\
\text { Aileal MNCs IL-6 in Pro -/+ } \\
\text { HRV \& Vac+Pro -/+ HRV } \\
\text { compared to Vac -/+ HRV \& } \\
\text { Control -/+ HRV } \\
\text { Aileal MNCs IL-10 in Vac+Pro } \\
\text {-HRV compared to Vac - HRV }\end{array}$ & $\begin{array}{l}\text { small intestinal anti-HRV IgA } \\
\text { and total IgA titers in Vac+Pro + } \\
\text { HRV compared to Vac + HRV } \\
\text { duodenal HRV IgA antibody- } \\
\text { secreting cell response in Vac } \\
\text { +Pro + HRV compared to Vac } \\
+ \text { +HRV } \\
\nabla \text { serum anti-HRV IgG antibody } \\
\text { and total IgG titers in Vac+Pro -/+ } \\
\text { HRV compared to Vac -/+ HRV } \\
\text { a CD21+CD2- B cells in ileum } \\
\text { and duodenum in Vac+Pro + HRV } \\
\text { compared to Vac + HRV }\end{array}$ & \\
\hline $\begin{array}{l}\text { Zhang H. et al., } \\
2014\end{array}$ & $\begin{array}{l}\text { Healthy stool, vaccinated -/+ } \\
\text { HRV challenge } \\
\text { Healthy stool +Pro, } \\
\text { vaccinated -/+ HRV } \\
\text { challenge }\end{array}$ & $\begin{array}{l}\text { Lactobacillus } \\
\text { rhamnosus strain GG } \\
\text { Healthy infant stool }\end{array}$ & no difference & no difference & & & \\
\hline $\begin{array}{l}\text { Twitchell et al., } \\
2016\end{array}$ & $\begin{array}{l}\text { Healthy stool, vaccinated -/+ } \\
\text { HRV challenge } \\
\text { Unhealthy stool, vaccinated } \\
\text {-/+ HRV challenge }\end{array}$ & $\begin{array}{l}\text { Healthy and unhealthy } \\
\text { (high enteropathy } \\
\text { score with minimal } \\
\text { seroconversion to } \\
\text { RW) Nicaraguan } \\
\text { infant stool }\end{array}$ & $\begin{array}{l}\boldsymbol{\nabla} \text { in Healthy stool } \\
+ \text { HRV vs } \\
\text { Unhealthy stool + } \\
\text { HRV }\end{array}$ & $\begin{array}{l}\boldsymbol{\nabla} \text { in Healthy stool } \\
+ \text { HRV vs } \\
\text { Unhealthy stool + } \\
\text { HRV }\end{array}$ & & $\begin{array}{l}\text { no difference in anti-HRV IgA, IgG } \\
\text { and virus neutralizing antibody } \\
\text { between groups }\end{array}$ & $\begin{array}{l}\text { Aileum, spleen and } \\
\text { blood virus-specific T } \\
\text { cell immune response } \\
\text { in Healthy - HRV } \\
\text { compared to Unhealthy } \\
\text { - HRV }\end{array}$ \\
\hline
\end{tabular}


and Kelkar, 2005; Perez-Cano et al., 2007), and both viremia and extraintestinal spread has been observed in rats infected with HRV or SRV (Crawford et al., 2006). In neonatal rats, probiotic LGG administration reduces SRV viral levels in serum and colon samples (Ventola et al., 2012). Furthermore, both live and dead LGG administration ameliorate the poor weight gain and colon swelling associated with SRV (Ventola et al., 2012). Gnotobiotic neonatal rats fed fermented milk containing probiotic Lactobacillus casei DN-114 001 exhibit reduced clinical measures of diarrhea, decreased vacuolation in intestinal epithelial cells, and decreased numbers of sulfated mucin containing cells (Guerin-Danan et al., 2001). If the rate of mucin secretion exceeds the rate of production then the absence of mucin containing cells are indicative of increased mucin secretion, a mechanism through which probiotics inhibit RV infection in mice (Kawahara et al., 2017). Bifidobacterium breve $\mathrm{M}-16 \mathrm{~V}$ has also been shown to reduce SRV-induced diarrheal severity and duration (Rigo-Adrover et al., 2017; Rigo-Adrover et al., 2018). In the absence of RV infection, $B$. breve $\mathrm{M}-16 \mathrm{~V}$ is sufficient to enhance IgA production, which may play a role in symptom reduction (Rigo-Adrover et al., 2016). A prebiotic mixture of short chain galactooligosaccharides and long chain fructooligosaccharides alone or in conjunction with B. breve $\mathrm{M}-16 \mathrm{~V}$ also reduces SRV diarrheal severity, duration and viral shedding, enhances early serum anti-RV IgG and intestinal anti-RV IgA responses, and increases IL-4 and IL-10, both of which reduce RV infection in animal models (Gandhi et al., 2017; Rigo-Adrover et al., 2017; Rigo-Adrover et al., 2018). Thus, data from neonatal rat models supports protective effects of probiotics against RV.

Despite multiple human clinical studies suggesting interactions between the gut microbiota and HRV infection, the cellular implications of these interactions remain unclear, supporting the utility of in vitro models. Bacterially produced or modified metabolites may be critical for mediating the effects of the microbiota on $\mathrm{RV}$, and can be readily tested using cell culture systems such as Caco2 or MA104 cells. Inhibitory effects of bile acids, which are regulated by the microbiota, on RV replication through activation of the farnesoid $\mathrm{X}$ receptor have been observed in both cell lines and mice (Kim and Chang, 2011). Indeed, exploration of how the metabolome, or the combined set of metabolites, present in the gut regulates RV infection will be an important area of future study.

Human intestinal organoids (HIOs) and enteroids (HIEs), which respectively use human induced pluripotent stem cells or culturing of epithelial crypt domains ex vivo, represent potentially useful systems for these studies (Kim and Chang, 2011; Yin et al., 2015; Saxena et al., 2016; Yin et al., 2016; Saxena et al., 2017). HIOs have been successfully used to cultivate HRV for analysis of antivirals (Finkbeiner et al., 2012; Yin et al., 2015; Yin et al., 2016), and HRV cultivation in HIEs has been used to study cellular mechanisms of HRV-induced diarrhea (Saxena et al., 2016) and to explore innate immune responses to HRV (Saxena et al., 2017). These systems thus hold promise for exploration of HRV-microbiota interactions (Blutt et al., 2018), though challenges in co-culturing eukaryotic cells and anaerobic gut microbes are non-trivial. Technical advances in replicating intestinal conditions in vitro may make these explorations increasingly feasible (Karve et al., 2017; JaliliFiroozinezhad et al., 2019; Shin et al., 2019), hopefully yielding future insight into the mechanisms of how the gut microbiota affects HRV.

\section{FUTURE DIRECTIONS}

Studies thus far support critical interactions between the host gut microbiota and RV infection as well as development of effective immune responses to RVV. However, much is still unknown about the nature of these interactions. Key remaining questions include: What are the key endogenous bacterial taxa influencing HRV infection and RVV responses? Do these taxa mediate effects via direct interactions with $\mathrm{RV}$, modulation of the host epithelium, or regulation of host cytokine pathways? Can pre-, pro-, or postbiotic (nutritional, bacterial, or bacterial product/ metabolite) interventions be improved to limit severity of HRV infection or enhance RVV responses?

Continued and expanded use of mouse, pig, and HIO/HIE models will be critical to further elucidate mechanisms of RV and microbiota interactions. Specific bacterial taxa, or other microbiota elements, that modulate infection and immune responses would be useful to identify in all models, as speciesspecific taxa may still mediate parallel effects on RV to provide common mechanistic insights. Further careful exploration of geographically diverse human cohorts in the context of natural HRV infection and RVV administration will also be critical to understand the complex environmental factors, including the microbiota, at play. Finally, continuous discourse between the human clinical study arena and experimental models to carefully test hypotheses will be key to advancing our capacity to combat $\mathrm{RV}$ infection in the future.

\section{AUTHOR CONTRIBUTIONS}

$\mathrm{AK}, \mathrm{MH}$, and $\mathrm{MB}$ wrote and edited the manuscript. $\mathrm{VH}$ edited the manuscript. All authors contributed to the article and approved the submitted version.

\section{FUNDING}

MB was supported by NIH grants R01 AI141716 and R01 OD024917, a Children's Discovery Institute of Washington University and St. Louis Children's Hospital Interdisciplinary Research Initiative grant (MI-II-2019-790), and The Mathers Foundation. AK was supported by T32 AI007163. MH was supported by a stipend from Washington University School of Medicine through the BioSURF program. 


\section{REFERENCES}

Ang, L., Arboleya, S., Lihua, G., Chuihui, Y., Nan, Q., Suarez, M., et al. (2014). The establishment of the infant intestinal microbiome is not affected by rotavirus vaccination. Sci. Rep. 4, 7417. doi: 10.1038/srep07417

Awachat, P. S., and Kelkar, S. D. (2005). Unexpected detection of simian SA11human reassortant strains of rotavirus G3P[8] genotype from diarrhea epidemic among tribal children of Western India. J. Med. Virol 77, 128-135. doi: $10.1002 / j m v .20425$

Blutt, S. E., Miller, A. D., Salmon, S. L., Metzger, D. W., and Conner, M. E. (2012). IgA is important for clearance and critical for protection from rotavirus infection. Mucosal Immunol. 5, 712-719. doi: 10.1038/mi.2012.51

Blutt, S. E., Crawford, S. E., Ramani, S., Zou, W. Y., and Estes, M. K. (2018). Engineered Human Gastrointestinal Cultures to Study the Microbiome and Infectious Diseases. Cell Mol. Gastroenterol. Hepatol 5, 241-251. doi: 10.1016/ j.jcmgh.2017.12.001

Boshuizen, J. A., Reimerink, J. H., Korteland-van Male, A. M., van Ham, V. J., Bouma, J., Gerwig, G. J., et al. (2005). Homeostasis and function of goblet cells during rotavirus infection in mice. Virology 337, 210-221. doi: 10.1016/ j.virol.2005.03.039

Broquet, A. H., Hirata, Y., McAllister, C. S., and Kagnoff, M. F. (2011). RIG-I/ MDA5/MAVS are required to signal a protective IFN response in rotavirusinfected intestinal epithelium. J. Immunol. 186, 1618-1626. doi: 10.4049/ jimmunol.1002862

Burke, R. M., Tate, J. E., Kirkwood, C. D., Steele, A. D., and Parashar, U. D. (2019). Current and new rotavirus vaccines. Curr. Opin. Infect. Dis. 32, 435-444. doi: 10.1097/QCO.0000000000000572

Chen, C. C., Baylor, M., and Bass, D. M. (1993). Murine intestinal mucins inhibit rotavirus infection. Gastroenterology 105, 84-92. doi: 10.1016/0016-5085(93) 90013-3

Chen, S. Y., Tsai, C. N., Lee, Y. S., Lin, C. Y., Huang, K. Y., Chao, H. C., et al. (2017). Intestinal microbiome in children with severe and complicated acute viral gastroenteritis. Sci. Rep. 7, 46130. doi: 10.1038/srep46130

Ciarlet, M., Conner, M. E., Finegold, M. J., and Estes, M. K. (2002). Group A rotavirus infection and age-dependent diarrheal disease in rats: a new animal model to study the pathophysiology of rotavirus infection. J. Virol 76, 41-57. doi: 10.1128/JVI.76.1.41-57.2002

Crawford, S. E., Patel, D. G., Cheng, E., Berkova, Z., Hyser, J. M., Ciarlet, M., et al. (2006). Rotavirus viremia and extraintestinal viral infection in the neonatal rat model. J. Virol 80, 4820-4832. doi: 10.1128/JVI.80.10.4820-4832.2006

Desselberger, U. (2014). Rotaviruses. Virus Res. 190, 75-96. doi: 10.1016/ j.virusres.2014.06.016

Dinleyici, E. C., Martinez-Martinez, D., Kara, A., Karbuz, A., Dalgic, N., Metin, O., et al. (2018). Time Series Analysis of the Microbiota of Children Suffering From Acute Infectious Diarrhea and Their Recovery After Treatment. Front. Microbiol 9, 1230. doi: 10.3389/fmicb.2018.01230

Duffy, L. C., Zielezny, M. A., Riepenhoff-Talty, M., Dryja, D., Sayahtaheri-Altaie, S., Griffiths, E., et al. (1994a). Reduction of virus shedding by B. bifidum in experimentally induced MRV infection. Statistical application for ELISA. Dig Dis. Sci. 39, 2334-2340. doi: 10.1007/BF02087647

Duffy, L. C., Zielezny, M. A., Riepenhoff-Talty, M., Dryja, D., Sayahtaheri-Altaie, S., Griffiths, E., et al. (1994b). Effectiveness of Bifidobacterium bifidum in mediating the clinical course of murine rotavirus diarrhea. Pediatr. Res. 35, 690-695. doi: 10.1203/00006450-199406000-00014

Engevik, M. A., Luk, B., Chang-Graham, A. L., Hall, A., Herrmann, B., Ruan, W., et al. (2019). Bifidobacterium dentium Fortifies the Intestinal Mucus Layer via Autophagy and Calcium Signaling Pathways. mBio 10 (3), e01087-19. doi: 10.1128/mBio.01087-19

Engevik, M. A., Banks, L. D., Engevik, K. A., Chang-Graham, A. L., Perry, J. L., Hutchinson, D. S., et al. (2020). Rotavirus infection induces glycan availability to promote ileum-specific changes in the microbiome aiding rotavirus virulence. Gut Microbes 11, 1324-1347. doi: 10.1080/19490976. 2020.1754714

Fang, S. B., Lee, H. C., Hu, J. J., Hou, S. Y., Liu, H. L., and Fang, H. W. (2009). Dose-dependent effect of Lactobacillus rhamnosus on quantitative reduction of faecal rotavirus shedding in children. J. Trop. Pediatr. 55, 297-301. doi: 10.1093/tropej/fmp001
Finkbeiner, S. R., Zeng, X. L., Utama, B., Atmar, R. L., Shroyer, N. F., and Estes, M. K. (2012). Stem cell-derived human intestinal organoids as an infection model for rotaviruses. MBio 3, e00159-e00112. doi: 10.1128/mBio.00159-12

Fix, J., Chandrashekhar, K., Perez, J., Bucardo, F., Hudgens, M. G., Yuan, L., et al. (2020). Association between Gut Microbiome Composition and Rotavirus Vaccine Response among Nicaraguan Infants. Am. J. Trop. Med. Hyg 102, 213 219. doi: 10.4269/ajtmh.19-0355

Gandhi, G. R., Santos, V. S., Denadai, M., da Silva Calisto, V. K., de Souza Siqueira Quintans, J., de Oliveira, E. S. A. M., et al. (2017). Cytokines in the management of rotavirus infection: A systematic review of in vivo studies. Cytokine 96, 152-160. doi: 10.1016/j.cyto.2017.04.013

Garcia-Lopez, R., Perez-Brocal, V., Diez-Domingo, J., and Moya, A. (2012). Gut microbiota in children vaccinated with rotavirus vaccine. Pediatr. Infect. Dis. J. 31, 1300-1302. doi: 10.1097/INF.0b013e318269e3ec

Grandy, G., Medina, M., Soria, R., Teran, C. G., and Araya, M. (2010). Probiotics in the treatment of acute rotavirus diarrhoea. A randomized, double-blind, controlled trial using two different probiotic preparations in Bolivian children. BMC Infect. Dis. 10, 253. doi: 10.1186/1471-2334-10-253

Greenberg, H. B., and Estes, M. K. (2009). Rotaviruses: from pathogenesis to vaccination. Gastroenterology 136, 1939-1951. doi: 10.1053/j.gastro.2009.02.076

Guerin-Danan, C., Meslin, J. C., Chambard, A., Charpilienne, A., Relano, P., Bouley, C., et al. (2001). Food supplementation with milk fermented by Lactobacillus casei DN-114 001 protects suckling rats from rotavirusassociated diarrhea. J. Nutr. 131, 111-117. doi: 10.1093/jn/131.1.111

Harris, V., Ali, A., Fuentes, S., Korpela, K., Kazi, M., Tate, J., et al. (2017a). Rotavirus vaccine response correlates with the infant gut microbiota composition in Pakistan. Gut Microbes 9 (2), 93-101. doi: 10.1080/19490976.2017.1376162

Harris, V. C., Armah, G., Fuentes, S., Korpela, K. E., Parashar, U., Victor, J. C., et al. (2017b). Significant Correlation Between the Infant Gut Microbiome and Rotavirus Vaccine Response in Rural Ghana. J. Infect. Dis. 215, 34-41. doi: 10.1093/infdis/jiw518

Harris, V. C., Haak, B. W., Handley, S. A., Jiang, B., Velasquez, D. E., Hykes, B. L. Jr., et al. (2018). Effect of Antibiotic-Mediated Microbiome Modulation on Rotavirus Vaccine Immunogenicity: A Human, Randomized-Control Proofof-Concept Trial. Cell Host Microbe 24, 197-207.e194. doi: 10.1016/ j.chom.2018.07.005

Harris, V. C. (2018). The Significance of the Intestinal Microbiome for Vaccinology: From Correlations to Therapeutic Applications. Drugs 78, 1063-1072. doi: 10.1007/s40265-018-0941-3

Hernandez, P. P., Mahlakoiv, T., Yang, I., Schwierzeck, V., Nguyen, N., Guendel, F., et al. (2015). Interferon-lambda and interleukin 22 act synergistically for the induction of interferon-stimulated genes and control of rotavirus infection. Nat. Immunol. 16, 698-707. doi: 10.1038/ni.3180

Huang, Y. F., Liu, P. Y., Chen, Y. Y., Nong, B. R., Huang, I. F., Hsieh, K. S., et al. (2014). Three-combination probiotics therapy in children with salmonella and rotavirus gastroenteritis. J. Clin. Gastroenterol. 48, 37-42. doi: 10.1097/ MCG.0b013e31828f1c6e

Ingle, H., Peterson, S. T., and Baldridge, M. T. (2018). Distinct Effects of Type I and III Interferons on Enteric Viruses. Viruses 10 (1), 46. doi: 10.3390/ v10010046

Ingle, H., Lee, S., Ai, T., Orvedahl, A., Rodgers, R., Zhao, G., et al. (2019). Viral complementation of immunodeficiency confers protection against enteric pathogens via interferon-lambda. Nat. Microbiol. 4, 1120-1128. doi: 10.1038/ s41564-019-0416-7

Isolauri, E., Joensuu, J., Suomalainen, H., Luomala, M., and Vesikari, T. (1995). Improved immunogenicity of oral $\mathrm{D} x \mathrm{RRV}$ reassortant rotavirus vaccine by Lactobacillus casei GG. Vaccine 13, 310-312. doi: 10.1016/0264-410X(95) 93319-5

Jalili-Firoozinezhad, S., Gazzaniga, F. S., Calamari, E. L., Camacho, D. M., Fadel, C. W., Bein, A., et al. (2019). A complex human gut microbiome cultured in an anaerobic intestine-on-a-chip. Nat. BioMed. Eng 3, 520-531. doi: 10.1038/ s41551-019-0397-0

Kandasamy, S., Chattha, K. S., Vlasova, A. N., Rajashekara, G., and Saif, L. J. (2014). Lactobacilli and Bifidobacteria enhance mucosal B cell responses and differentially modulate systemic antibody responses to an oral human rotavirus vaccine in a neonatal gnotobiotic pig disease model. Gut Microbes. 5 (5), 639651. doi: 10.4161/19490976.2014.969972 
Kandasamy, S., Vlasova, A. N., Fischer, D., Kumar, A., Chattha, K. S., Rauf, A., et al. (2016). Differential Effects of Escherichia coli Nissle and Lactobacillus rhamnosus Strain GG on Human Rotavirus Binding, Infection, and B Cell Immunity. J. Immunol. 196, 1780-1789. doi: 10.4049/jimmunol.1501705

Karve, S. S., Pradhan, S., Ward, D. V., and Weiss, A. A. (2017). Intestinal organoids model human responses to infection by commensal and Shiga toxin producing Escherichia coli. PloS One 12, e0178966. doi: 10.1371/journal.pone.0178966

Kawahara, T., Makizaki, Y., Oikawa, Y., Tanaka, Y., Maeda, A., Shimakawa, M., et al. (2017). Oral administration of Bifidobacterium bifidum G9-1 alleviates rotavirus gastroenteritis through regulation of intestinal homeostasis by inducing mucosal protective factors. PloS One 12, e0173979. doi: 10.1371/ journal.pone.0173979

Kennedy, E. A., King, K. Y., and Baldridge, M. T. (2018). Mouse Microbiota Models: Comparing Germ-Free Mice and Antibiotics Treatment as Tools for Modifying Gut Bacteria. Front. Physiol. 9, 1534. doi: 10.3389/fphys.2018.01534

Kim, Y., and Chang, K. O. (2011). Inhibitory effects of bile acids and synthetic farnesoid X receptor agonists on rotavirus replication. J. Virol 85, 1257012577. doi: 10.1128/JVI.05839-11

Kumar, A., Vlasova, A. N., Deblais, L., Huang, H. C., Wijeratne, A., Kandasamy, S., et al. (2018). Impact of nutrition and rotavirus infection on the infant gut microbiota in a humanized pig model. BMC Gastroenterol. 18, 93. doi: 10.1186/ s12876-018-0810-2

Lazarus, R. P., John, J., Shanmugasundaram, E., Rajan, A. K., Thiagarajan, S., Giri, S., et al. (2018). The effect of probiotics and zinc supplementation on the immune response to oral rotavirus vaccine: A randomized, factorial design, placebo-controlled study among Indian infants. Vaccine 36, 273-279. doi: 10.1016/j.vaccine.2017.07.116

Lee, D. K., Park, J. E., Kim, M. J., Seo, J. G., Lee, J. H., and Ha, N. J. (2015). Probiotic bacteria, B. longum and $\mathrm{L}$. acidophilus inhibit infection by rotavirus in vitro and decrease the duration of diarrhea in pediatric patients. Clin. Res. Hepatol Gastroenterol. 39, 237-244. doi: 10.1016/j.clinre.2014.09.006

Lin, J. D., Feng, N., Sen, A., Balan, M., Tseng, H. C., McElrath, C., et al. (2016). Distinct Roles of Type I and Type III Interferons in Intestinal Immunity to Homologous and Heterologous Rotavirus Infections. PloS Pathog 12, e1005600. doi: 10.1371/journal.ppat.1005600

Ma, C., Wu, X., Nawaz, M., Li, J., Yu, P., Moore, J. E., et al. (2011). Molecular characterization of fecal microbiota in patients with viral diarrhea. Curr. Microbiol 63, 259-266. doi: 10.1007/s00284-011-9972-7

Meurens, F., Summerfield, A., Nauwynck, H., Saif, L., and Gerdts, V. (2012). The pig: a model for human infectious diseases. Trends Microbiol 20, 50-57. doi: 10.1016/j.tim.2011.11.002

Munoz, J. A., Chenoll, E., Casinos, B., Bataller, E., Ramon, D., Genoves, S., et al. (2011). Novel probiotic Bifidobacterium longum subsp. infantis CECT 7210 strain active against rotavirus infections. Appl. Environ. Microbiol 77, 87758783. doi: 10.1128/AEM.05548-11

O'Ryan, M. (2017). Rotavirus Vaccines: a story of success with challenges ahead. F1000Res 6, 1517. doi: 10.12688/f1000research.11912.1

Paim, F. C., Langel, S. N., Fischer, D. D., Kandasamy, S., Shao, L., Alhamo, M. A., et al. (2016). Effects of Escherichia coli Nissle 1917 and Ciprofloxacin on small intestinal epithelial cell mRNA expression in the neonatal piglet model of human rotavirus infection. Gut Pathog 8, 66. doi: 10.1186/s13099-016-0148-7

Parashar, U. D., Hummelman, E. G., Bresee, J. S., Miller, M. A., and Glass, R. I. (2003). Global illness and deaths caused by rotavirus disease in children. Emerg Infect. Dis. 9, 565-572. doi: 10.3201/eid0905.020562

Parker, E. P. K., Praharaj, I., Zekavati, A., Lazarus, R. P., Giri, S., Operario, D. J., et al. (2018). Influence of the intestinal microbiota on the immunogenicity of oral rotavirus vaccine given to infants in south India. Vaccine 36, 264-272. doi: 10.1016/j.vaccine.2017.11.031

Patel, M., Glass, R. I., Jiang, B., Santosham, M., Lopman, B., and Parashar, U. (2013). A systematic review of anti-rotavirus serum IgA antibody titer as a potential correlate of rotavirus vaccine efficacy. J. Infect. Dis. 208, 284-294. doi: 10.1093/infdis/jit166

Payne, D. C., Staat, M. A., Edwards, K. M., Szilagyi, P. G., Weinberg, G. A., Hall, C. B., et al. (2011). Direct and indirect effects of rotavirus vaccination upon childhood hospitalizations in 3 US Countie-2009. Clin. Infect. Dis. 53, 245-253. doi: $10.1093 / \mathrm{cid} / \mathrm{cir} 307$

Perez-Cano, F. J., Castell, M., Castellote, C., and Franch, A. (2007). Characterization of clinical and immune response in a rotavirus diarrhea model in suckling Lewis rats. Pediatr. Res. 62, 658-663. doi: 10.1203/ PDR.0b013e318159a273

Pott, J., Mahlakoiv, T., Mordstein, M., Duerr, C. U., Michiels, T., Stockinger, S., et al. (2011). IFN-lambda determines the intestinal epithelial antiviral host defense. Proc. Natl. Acad. Sci. U.S.A. 108, 7944-7949. doi: 10.1073/ pnas. 1100552108

Preidis, G. A., Saulnier, D. M., Blutt, S. E., Mistretta, T. A., Riehle, K. P., Major, A. M., et al. (2012). Host response to probiotics determined by nutritional status of rotavirus-infected neonatal mice. J. Pediatr. Gastroenterol. Nutr. 55, 299-307. doi: 10.1097/MPG.0b013e31824d2548

Qiao, H., Duffy, L. C., Griffiths, E., Dryja, D., Leavens, A., Rossman, J., et al. (2002). Immune responses in rhesus rotavirus-challenged $\mathrm{BALB} / \mathrm{c}$ mice treated with bifidobacteria and prebiotic supplements. Pediatr. Res. 51, 750-755. doi: 10.1203/00006450-200206000-00015

Rigo-Adrover, M. D., Franch, A., Castell, M., and Perez-Cano, F. J. (2016). Preclinical Immunomodulation by the Probiotic Bifidobacterium breve M$16 \mathrm{~V}$ in Early Life. PloS One 11, e0166082. doi: 10.1371/journal. pone. 0166082

Rigo-Adrover, M., Saldana-Ruiz, S., van Limpt, K., Knipping, K., Garssen, J., Knol, J., et al. (2017). A combination of scGOS/lcFOS with Bifidobacterium breve M$16 \mathrm{~V}$ protects suckling rats from rotavirus gastroenteritis. Eur. J. Nutr. 56, 1657-1670. doi: 10.1007/s00394-016-1213-1

Rigo-Adrover, M. D. M., van Limpt, K., Knipping, K., Garssen, J., Knol, J., Costabile, A., et al. (2018). Preventive Effect of a Synbiotic Combination of Galacto- and Fructooligosaccharides Mixture With Bifidobacterium breve M$16 \mathrm{~V}$ in a Model of Multiple Rotavirus Infections. Front. Immunol. 9, 1318. doi: 10.3389/fimmu.2018.01318

Rodriguez, W. J., Kim, H. W., Brandt, C. D., Bise, B., Kapikian, A. Z., Chanock, R. M., et al. (1980). Rotavirus gastroenteritis in the Washington, DC, area: incidence of cases resulting in admission to the hospital. Am. J. Dis. Child 134, 777-779. doi: 10.1001/archpedi.1980.02130200047015

Saavedra, J. M., Bauman, N. A., Oung, I., Perman, J. A., and Yolken, R. H. (1994). Feeding of Bifidobacterium bifidum and Streptococcus thermophilus to infants in hospital for prevention of diarrhoea and shedding of rotavirus. Lancet 344, 1046-1049. doi: 10.1016/S0140-6736(94)91708-6

Saif, L. J., Ward, L. A., Yuan, L., Rosen, B. I., and To, T. L. (1996). The gnotobiotic piglet as a model for studies of disease pathogenesis and immunity to human rotaviruses. Arch. Virol Suppl. 12, 153-161. doi: 10.1007/978-3-70916553-9_17

Saxena, K., Blutt, S. E., Ettayebi, K., Zeng, X. L., Broughman, J. R., Crawford, S. E., et al. (2016). Human Intestinal Enteroids: a New Model To Study Human Rotavirus Infection, Host Restriction, and Pathophysiology. J. Virol 90, 43-56. doi: 10.1128/JVI.01930-15

Saxena, K., Simon, L. M., Zeng, X. L., Blutt, S. E., Crawford, S. E., Sastri, N. P., et al. (2017). A paradox of transcriptional and functional innate interferon responses of human intestinal enteroids to enteric virus infection. Proc. Natl. Acad. Sci. U.S.A. 114, E570-E579. doi: 10.1073/pnas.1615422114

Schnadower, D., Tarr, P. I., Casper, T. C., Gorelick, M. H., Dean, J. M., O’Connell, K. J., et al. (2018). Lactobacillus rhamnosus GG versus Placebo for Acute Gastroenteritis in Children. N Engl. J. Med. 379, 2002-2014. doi: 10.1056/ NEJMoa1 802598

Shi, Z., Zou, J., Zhang, Z., Zhao, X., Noriega, J., Zhang, B., et al. (2019). Segmented Filamentous Bacteria Prevent and Cure Rotavirus Infection. Cell 179, 644-658 e613. doi: 10.1016/j.cell.2019.09.028

Shin, W., Wu, A., Massidda, M. W., Foster, C., Thomas, N., Lee, D. W., et al. (2019). A Robust Longitudinal Co-culture of Obligate Anaerobic Gut Microbiome With Human Intestinal Epithelium in an Anoxic-Oxic Interface-on-a-Chip. Front. Bioeng Biotechnol. 7, 13. doi: 10.3389/ fbioe. 2019.00013

Tate, J. E., Burton, A. H., Boschi-Pinto, C., Parashar, U. D., and World Health Organization-Coordinated Global Rotavirus Surveillance, N. (2016). Global, Regional, and National Estimates of Rotavirus Mortality in Children $<5$ Years of Age 2000-2013. Clin. Infect. Dis. 62 Suppl 2, S96-S105. doi: 10.1093/cid/ civ1013

Teran, C. G., Teran-Escalera, C. N., and Villarroel, P. (2009). Nitazoxanide vs. probiotics for the treatment of acute rotavirus diarrhea in children: a randomized, single-blind, controlled trial in Bolivian children. Int. J. Infect. Dis. 13, 518-523. doi: 10.1016/j.ijid.2008.09.014 
Twitchell, E. L., Tin, C., Wen, K., Zhang, H., Becker-Dreps, S., Azcarate-Peril, M. A., et al. (2016). Modeling human enteric dysbiosis and rotavirus immunity in gnotobiotic pigs. Gut Pathog 8, 51. doi: 10.1186/s13099-016-0136-y

Uchiyama, R., Chassaing, B., Zhang, B., and Gewirtz, A. T. (2014). Antibiotic treatment suppresses rotavirus infection and enhances specific humoral immunity. J. Infect. Dis. 210, 171-182. doi: 10.1093/infdis/jiu037

Ventola, H., Lehtoranta, L., Madetoja, M., Simonen-Tikka, M. L., Maunula, L., Roivainen, M., et al. (2012). Effects of the viability of Lactobacillus rhamnosus GG on rotavirus infection in neonatal rats. World J. Gastroenterol. 18, 59255931. doi: 10.3748/wjg.v18.i41.5925

Vesikari, T., Matson, D. O., Dennehy, P., Van Damme, P., Santosham, M., Rodriguez, Z., et al. (2006). Safety and efficacy of a pentavalent humanbovine (WC3) reassortant rotavirus vaccine. N Engl. J. Med. 354, 23-33. doi: 10.1056/NEJMoa052664

Vesikari, T., Itzler, R., Karvonen, A., Korhonen, T., Van Damme, P., Behre, U., et al. (2009). RotaTeq, a pentavalent rotavirus vaccine: efficacy and safety among infants in Europe. Vaccine 28, 345-351. doi: 10.1016/ j.vaccine.2009.10.041

Vlasova, A. N., Chattha, K. S., Kandasamy, S., Liu, Z., Esseili, M., Shao, L., et al. (2013). Lactobacilli and bifidobacteria promote immune homeostasis by modulating innate immune responses to human rotavirus in neonatal gnotobiotic pigs. PloS One 8, e76962. doi: 10.1371/journal.pone.0076962

Ward, R. L., and Bernstein, D. I. (2009). Rotarix: a rotavirus vaccine for the world. Clin. Infect. Dis. 48, 222-228. doi: 10.1086/595702

Yin, Y., Bijvelds, M., Dang, W., Xu, L., van der Eijk, A. A., Knipping, K., et al. (2015). Modeling rotavirus infection and antiviral therapy using primary intestinal organoids. Antiviral Res. 123, 120-131. doi: 10.1016/ j.antiviral.2015.09.010

Yin, Y., Wang, Y., Dang, W., Xu, L., Su, J., Zhou, X., et al. (2016). Mycophenolic acid potently inhibits rotavirus infection with a high barrier to resistance development. Antiviral Res. 133, 41-49. doi: 10.1016/j.antiviral.2016.07.017

Yuan, L., and Saif, L. J. (2002). Induction of mucosal immune responses and protection against enteric viruses: rotavirus infection of gnotobiotic pigs as a model. Vet Immunol. Immunopathol 87, 147-160. doi: 10.1016/S0165-2427 (02)00046-6

Zhang, W., Azevedo, M. S., Gonzalez, A. M., Saif, L. J., Van Nguyen, T., Wen, K., et al. (2008a). Influence of probiotic Lactobacilli colonization on neonatal B cell responses in a gnotobiotic pig model of human rotavirus infection and disease. Vet Immunol. Immunopathol 122, 175-181. doi: 10.1016/ j.vetimm.2007.10.003

Zhang, W., Azevedo, M. S., Wen, K., Gonzalez, A., Saif, L. J., Li, G., et al. (2008b). Probiotic Lactobacillus acidophilus enhances the immunogenicity of an oral rotavirus vaccine in gnotobiotic pigs. Vaccine 26, 3655-3661. doi: 10.1016/ j.vaccine.2008.04.070

Zhang, M., Zhang, M., Zhang, C., Du, H., Wei, G., Pang, X., et al. (2009). Pattern extraction of structural responses of gut microbiota to rotavirus infection via multivariate statistical analysis of clone library data. FEMS Microbiol Ecol. 70, 21-29. doi: 10.1111/j.1574-6941.2008.00604.x

Zhang, B., Chassaing, B., Shi, Z., Uchiyama, R., Zhang, Z., Denning, T. L., et al. (2014). Viral infection. Prevention and cure of rotavirus infection via TLR5/ NLRC4-mediated production of IL-22 and IL-18. Science 346, 861-865. doi: 10.1126/science.1256999

Zhang, H., Wang, H., Shepherd, M., Wen, K., Li, G., Yang, X., et al. (2014). Probiotics and virulent human rotavirus modulate the transplanted human gut microbiota in gnotobiotic pigs. Gut Pathog 6, 39. doi: 10.1186/s13099-014-0039-8

Conflict of Interest: The authors declare that the research was conducted in the absence of any commercial or financial relationships that could be construed as a potential conflict of interest.

Copyright (c) 2021 Kim, Hogarty, Harris and Baldridge. This is an open-access article distributed under the terms of the Creative Commons Attribution License (CC BY). The use, distribution or reproduction in other forums is permitted, provided the original author(s) and the copyright owner(s) are credited and that the original publication in this journal is cited, in accordance with accepted academic practice. No use, distribution or reproduction is permitted which does not comply with these terms. 